\title{
Estudo da ativação ácida e tratamento térmico de bauxita extraída de jazidas em Minas Gerais, Brasil
}

\section{(Study of acid activation and thermal treatment of bauxite extracted from deposits in Minas Gerais, Brazil)}

\author{
C. M. R. Prado M. I. R. Alves ${ }^{1}$, M. I. G. Leles ${ }^{1}$, R. I. Medeiros ${ }^{1}$, C. R. N. Otto ${ }^{1}$, F. C. Damasceno , \\ C. H. H. Brait ${ }^{2}$, P. I. B. M. Franco ${ }^{1}$, N. R. Antoniosi Filho \\ ${ }^{1}$ Instituto de Química, Universidade Federal de Goiás, Campus II, Samambaia, Goiânia, GO 74001-970 \\ ${ }^{2}$ Laboratório Exata, R. 100 173, Jd. Rio Claro, Jatai, GO 75802-005 \\ cinaramrp@hotmail.com
}

\begin{abstract}
Resumo
O Brasil é um dos maiores produtores mundiais de bauxita, contudo pouco se conhece sobre as características químicas e mineralógicas desse mineral. Assim sendo, este trabalho tem por objetivo dar prosseguimento à caracterização de bauxita, estudando as transformações ocorridas nesse material quando submetido à ativação ácida e ao tratamento térmico. Os resultados demonstraram que a bauxita "in natura" é composta basicamente pelo mineral gibbsita, seguido de semicristalitos de goethita e óxido de silício, apresentando característica de sólido com ausência de mesoporosidade, com baixos valores de área superficial total, diâmetro e volume de poros. As modificações químicas e físicas que ocorrem no material durante a calcinação são governadas, principalmente, pela desidratação das fases de hidróxidos de alumínio presentes, levando à formação das fases boehmita, hematita e alfa alumina, além de resultar em aumento na porosidade e na área superficial da bauxita. As bauxitas ativadas em meio ácido mostraram que as transformações sofridas no sólido estão diretamente relacionadas com a concentração da solução ácida utilizada e resultam em aumento da área superficial total, diâmetro e volume de poros.
\end{abstract}

Palavras-chave: ativação ácida, bauxita, calcinação.

\begin{abstract}
Brazil is one of the world's leading producers of bauxite. Little is known, however, about the chemical and mineralogical characteristics of Brazilian bauxite. The objective of this paper is to characterize bauxite in both natural and thermally and chemically activated forms. The transformations occurring during these two processes are described. The results show that the raw bauxite is basically composed of the mineral gibbsite, followed by semicrystalites of goethite and silicon oxide. Its characteristics are those of a solid without mesoporosity, with small total surface area and pore diameter and volume. The chemical and physical modifications that occur in the material during the calcination process are governed mainly by the dehydration of the aluminum hydroxides phases, leading to the formation of the boehmite, hematite and alpha alumina phases. Calcination results in an increase in the porosity and surface area of the bauxite as well as the appearance of the characteristics of mesoporous and thermally stable materials. The activation of bauxites in an acid medium showed that the transformations in the solid are directly related to the concentration of the acid solution used and result in an increase in the total surface area and pore diameter and volume.
\end{abstract}

Keywords: acid activation, bauxite, calcination.

\section{INTRODUÇÃO}

A bauxita é uma rocha residual composta, principalmente, de um ou mais tipos de hidróxido de alumínio (gibbsita, boehmita, diásporo), óxidos e hidróxidos de ferro, sílica, argilominerais, óxidos de titânio e traços de outros elementos [1]. Mais de $90 \%$ da produção mundial de bauxita é utilizada para produção de alumina pelo processo Bayer; visando, principalmente, à redução ao alumínio metálico $(85 \%)$. O restante da produção $(10 \%)$ destina-se a vários setores de produtos não metálicos como: refratários, abrasivos, cimentos, químicos e fabricação de aço [2]. A concentração dos minerais de alumínio presentes na bauxita varia dependendo da localização geográfica do minério. As bauxitas ricas em boehmita são encontradas em depósitos europeus (França e Grécia), enquanto que aquelas ricas em diásporos, na China, Hungria e Romênia. As bauxitas geologicamente mais novas possuem alto conteúdo de gibbsita, ocorrem em grandes depósitos em áreas de clima tropical como Jamaica, Brasil, Austrália, Guiné, Guiana, Suriname e Índia, e são as que apresentam maior interesse comercial [3]. As principais reservas de bauxita, perfazendo um total de 55 a 75 bilhões de toneladas, são encontradas na América do Sul (33\%), África (27\%), Ásia (17\%) e Oceania $(13 \%)$, sendo que as três maiores localizam-se na Guiné $\left(1^{\mathrm{a}}\right)$, no Brasil ( $\left.2^{\mathrm{a}}\right)$ e na Austrália (3 $3^{\mathrm{a}}$ [4]. 
As bauxitas em seu estado natural não têm sido consideradas satisfatórias para a aplicação industrial. Desta forma faz-se necessário uma etapa de calcinação da bauxita "in natura" com os seguintes objetivos: obter a completa eliminação da água presente no minério e formar as fases alumina alfa e mulita, que aumentam a refratariedade, densidade e consistência do material [5].

Outro tratamento que pode ser empregado a fim de melhorar as propriedades químicas e texturais dos argilominerais é o tratamento químico, realizado por meio da ativação com ácidos inorgânicos. Esse tipo de tratamento de uma forma geral propicia o aumento da área específica do sólido, devido à desorganização da estrutura, pela eliminação de diversas impurezas minerais e pela criação de mesoporos. Além disso, ocorre a substituição de cátions alcalinos e/ou alcalinosterrosos, presentes na estrutura cristalina ou como cátions intercalados trocáveis, por cátions hidroxônio, $\mathrm{H}_{3} \mathrm{O}^{+}[2,6-7]$.

Estudos avaliaram o potencial catalítico da bauxita calcinada na reação de craqueamento termo-catalítico para produção de biocombustíveis a partir de óleo de soja [8]. Os resultados mostraram altos rendimentos em biocombustíveis líquidos e gasosos, que variaram de $77 \%$ a $79 \%$, sendo a mistura formada composta por hidrocarbonetos, tais como alcanos, alcenos e aromáticos.

O objetivo deste trabalho é a caracterização da bauxita in natura de Poços de Caldas, MG, após ter sido submetida ao processo de calcinação e ao tratamento ácido, a fim de analisar as modificações químicas e físicas desenvolvidas na bauxita.

\section{MATERIAIS E MÉTODOS}

Foram estudadas as amostras de bauxitas in natura e calcinada fornecidas pela empresa Mineradora Curimbaba, Poços de Caldas, MG. No processo de calcinação realizado pela mineradora para obtenção da bauxita calcinada, empregase forno rotativo a aproximadamente $1100{ }^{\circ} \mathrm{C}$. O tratamento ácido foi realizado na amostra de bauxita calcinada. Para os ensaios de ativação tratou-se uma quantidade de bauxita em ácido clorídrico a $10 \%(\mathrm{~m} / \mathrm{v})$ sob refluxo a $90{ }^{\circ} \mathrm{C}$, durante 2 h. Utilizou-se solução de ácido clorídrico nas concentrações de 1,0 mol.L $\mathrm{L}^{-1}$ e 4,0 mol.L $\mathrm{L}^{-1}$. Os sólidos obtidos após esse tratamento foram lavados e posteriormente colocados para secar a $110^{\circ} \mathrm{C}$ por $6 \mathrm{~h}$.
Para efetuar quantificação dos principais metais nas bauxitas, utilizou-se a técnica de ICP-OES. As amostras foram processadas via úmida por digestão ácida e analisadas num espectrômetro de emissão ótica com visualização radial e axial (ICP-OES Perkin Elmer Optima 5300 DV). As linhas de emissão utilizadas $(\mathrm{nm})$ foram escolhidas considerando sua maior sensibilidade e a ausência de interferências: Al (396,153), Si (251,611), Fe $(238,204)$, Na $(589,592)$, K (766,490), Ca $(317,933)$ e $\mathrm{Mg}(285,213)$.

Os espectros de absorção na região do infravermelho foram obtidos em um espectrômetro de infravermelho com transformada de Fourier Bomen MB-Series. As amostras foram prensadas em pastilhas de $\mathrm{KBr}$ e analisadas em comprimentos de onda na faixa de 4000 a $400 \mathrm{~cm}^{-1}$.

As curvas TG foram obtidas no equipamento Mettler Toledo, TGAS/DTA $851^{\mathrm{e}}$ de $25{ }^{\circ} \mathrm{C}$ até $1400{ }^{\circ} \mathrm{C}$, massa de amostra de $\sim 7 \mathrm{mg}$, cadinho de $\alpha$-alumina de $140 \mu \mathrm{L}$, e taxa de aquecimento de $15^{\circ} \mathrm{C} \cdot \mathrm{min}^{-1}$ em atmosfera de nitrogênio com um fluxo de $50 \mathrm{~mL} \cdot \mathrm{min}^{-1}$.

As análises por difração de raios $\mathrm{X}$ foram feitas em um difratômetro Shimadzu DRX6000, com radiação $\mathrm{k}_{\alpha}$ do cobre, varredura contínua em teta-2teta, com velocidade de 2 graus/ min em intervalos de 0,02 grau e o intervalo de medida, em $2 \theta$, de $10^{\circ}$ a $80^{\circ}$. Para interpretação dos resultados utilizouse o banco de dados JCPDS para identificação das fases.

A área superficial específica, o volume total de poros, o diâmetro médio dos poros e a distribuição de tamanho de poros foram determinados por meio de dados de adsorção e dessorção de nitrogênio a diferentes pressões relativas na temperatura do nitrogênio líquido, em aparelho Micromeritics ASAP-2010.

\section{RESULTADOS E DISCUSSÃO}

A Tabela I apresenta a composição química das bauxitas estudadas obtida através das análises por ICP-OES.

A análise da bauxita in natura mostra que o percentual de alumínio é predominante sobre os outros elementos presente, indicando um material com boas propriedades refratárias [9]. $\mathrm{O}$ nível de Fe presente confere à bauxita coloração vermelha. Os demais compostos presentes apresentam concentração abaixo de 1\%. $\mathrm{Ca}, \mathrm{Mg}, \mathrm{Na}$ e $\mathrm{K}$ são agentes fundentes e tendem a baixar a refratariedade. Para a amostra de bauxita calcinada verifica-se aumento nos percentuais de Al, Si e

Tabela I - Composição percentual dos principais elementos químicos presentes nas amostras de bauxita. [Table I - Percentages of the chemical composition present in the bauxites samples.]

\begin{tabular}{cccccccc}
\hline \multirow{2}{*}{ Amostra } & \multicolumn{7}{c}{ Percentual em massa } \\
\cline { 2 - 8 } & $\mathrm{Al}$ & $\mathrm{Si}$ & $\mathrm{Fe}$ & $\mathrm{Ca}$ & $\mathrm{Mg}$ & $\mathrm{K}$ & $\mathrm{Na}$ \\
\hline Bauxita "in natura" & 28,32 & 5,07 & 4,90 & 0,04 & 0,01 & 0,23 & 0,11 \\
Bauxita calcinada & 35,88 & 6,01 & 5,77 & 0,08 & 0,02 & 0,32 & 0,10 \\
Bauxita ativada com HCl 1 mol.L"-1 & 35,31 & 6,48 & 5,97 & 0,08 & 0,02 & 0,36 & 0,11 \\
Bauxita ativada com HCl 4 mol.L-1 & 33,77 & 9,78 & 0,47 & 0,11 & 0,02 & 0,32 & 0,13 \\
\hline
\end{tabular}


Fe; isto se deve à eliminação de toda água de hidratação e constituição presente na bauxita in natura após o processo de calcinação. Os resultados da composição química das bauxitas ativadas com ácido mostram que a percentagem de dissolução de ferro e alumínio presente na bauxita depende da concentração da solução de ácido clorídrico utilizada. Como pode ser observado na Tabela I, a dissolução de ferro e de alumínio foram respectivamente de $91,85 \%$ e $5,88 \%$, para a bauxita ativada em $\mathrm{HCl} 4 \mathrm{~mol} . \mathrm{L}^{-1}$, sendo que para a bauxita ativada em $\mathrm{HCl} 1 \mathrm{~mol} . \mathrm{L}^{-1}$ a dissolução de ferro não foi observada, ocorrendo apenas para o alumínio na proporção de 1,59\%. Observa-se aumento do percentual de óxido de silício de $8,07 \%$ para a bauxita ativada em $\mathrm{HCl}$ 4 mol. $\mathrm{L}^{-1}$ devido a alta solubilidade do ferro comparado ao silício.

Na remoção de ferro e alumínio presentes na bauxita tratada com ácido clorídrico, a percentagem de dissolução do ferro aumenta gradualmente de $10 \%$ a $98 \%$ com o aumento da concentração da solução ácida de 1,0 a 4,0 mol.L $\mathrm{L}^{-1}$, e alcança $100 \%$ numa concentração de 5 mol.L $\mathrm{L}^{-1}$ [10]. Em relação ao percentual de alumínio dissolvido a faixa encontra-se entre 5,2 a $6,9 \%$.

As Figs.1 e 2 apresentam os espectros na região do infravermelho das bauxitas em estudo.

$\mathrm{O}$ espectro de infravermelho da bauxita in natura (Fig. 1a) apresenta bandas finas e de pequenas intensidades que aparecem nas freqüências de 3696, 3624, 3533, 3455 e $3387 \mathrm{~cm}^{-1}$. Tais bandas são atribuídas à deformação axial do grupo hidroxila de água adsorvida $\left[v_{s}(\mathrm{O}-\mathrm{H})\right]$ e por ligação de hidrogênio fisicamente $[v(\mathrm{Al}-\mathrm{OH})]$. As bandas situadas em 1023,968 e $913 \mathrm{~cm}^{-1}$ são atribuidas à deformação angular do grupo hidroxila da fase gibbsita. No espectro da bauxita calcinada (Fig. 1b) verifica-se uma banda larga acima de 3000 $\mathrm{cm}^{-1}$ referente às freqüências vibracionais do grupo hidroxila da fase boehmita e as bandas de deformação angular da hidroxila em 1070, 768 e $589 \mathrm{~cm}^{-1}$ dessa mesma fase [11-13].

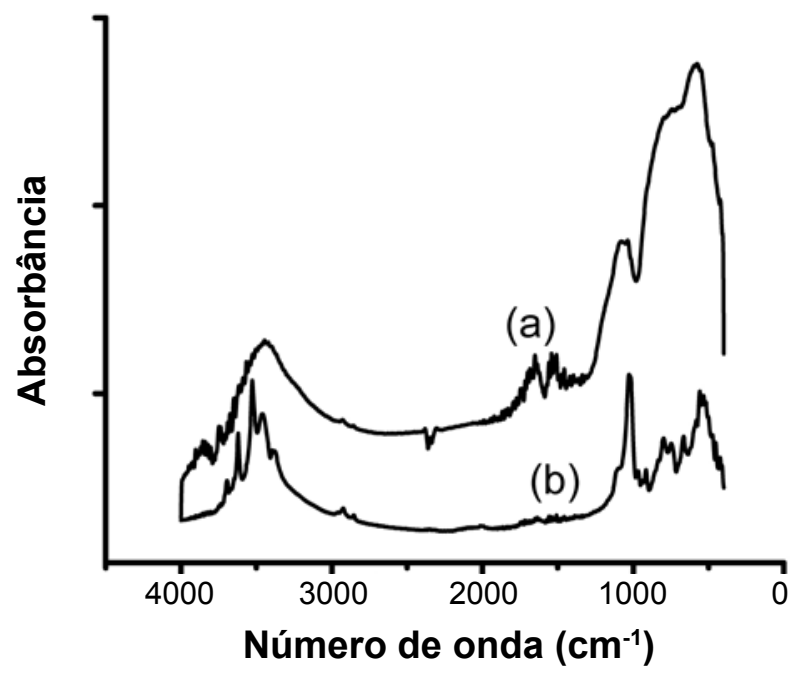

Figura 1: Espectros na região do infravermelho da bauxita in natura (a) e da bauxita calcinada (b).

[Figure 1: FTIR spectra of: raw bauxite (a) and calcined bauxite (b).]

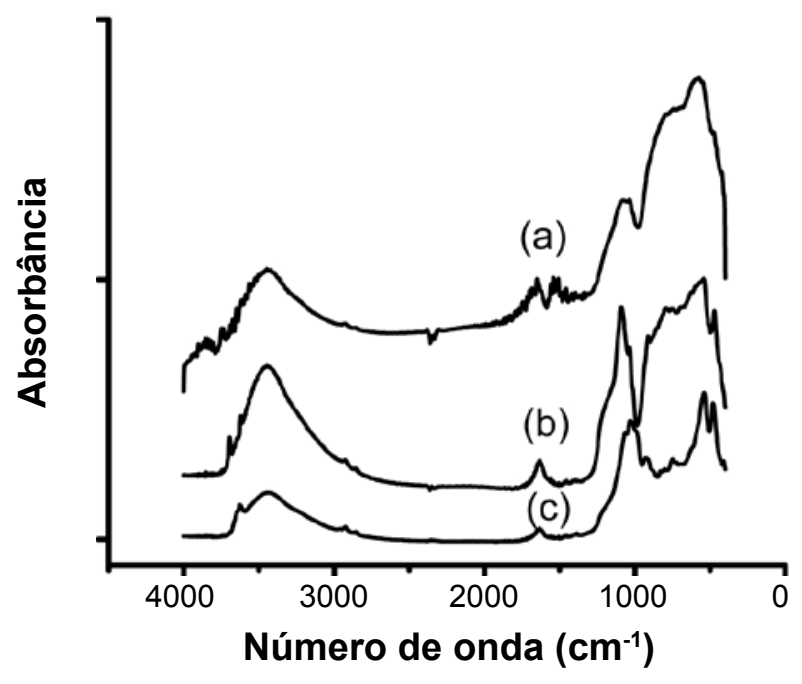

Figura 2: Espectros na região do infravermelho da bauxita calcinada (a) e das bauxitas ativadas em solução de ácido clorídrico 1,0 mol.L -1 $^{-1}$ (b) e 4,0 mol.L L $^{-1}$ (c).

[Figure 2: Infrared spectra of calcined bauxite (a) and bauxite activated in 1.0 mol.L $L^{-1}$ (b) and 4.0 mol.L $L^{-1}$ (c) HCl solutions.]

Nos espectros de absorção de infravermelho para bauxitas ativadas em solução de ácido clorídrico 1,0 mol.L $\mathrm{L}^{-1}$ e 4,0 mol.L $\mathrm{L}^{-1}$ (Fig. 2) observam-se as bandas intensas e largas referentes às freqüências vibracionais do grupo hidroxila da fase boehmita em 1091, 783, $555 \mathrm{~cm}^{-1} \mathrm{e}$ acima de $3000 \mathrm{~cm}^{-1}$ para a bauxita ativada com $\mathrm{HCl} 1,0 \mathrm{~mol} . \mathrm{L}^{-1}$, e para a bauxita

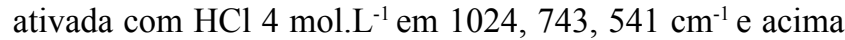
de $3000 \mathrm{~cm}^{-1}$. Essas bandas foram semelhantes às verificadas na amostra da bauxita calcinada sem tratamento ácido. Logo, a ativação ácida não promove modificações químicas em relação aos hidróxidos de alumínio da fase boehmita.

A Fig. 3 mostra as curvas TG da bauxita in natura (d), da bauxita calcinada (a) e das bauxitas ativadas em ácido clorídrico 1,0 mol.L-1 (b) e 4,0 mol.L $\mathrm{L}^{-1}$ (c). Na curva TG da bauxita in natura observam-se três etapas de perda de massa. A primeira etapa, de 19,26\%, na faixa de temperatura de 220

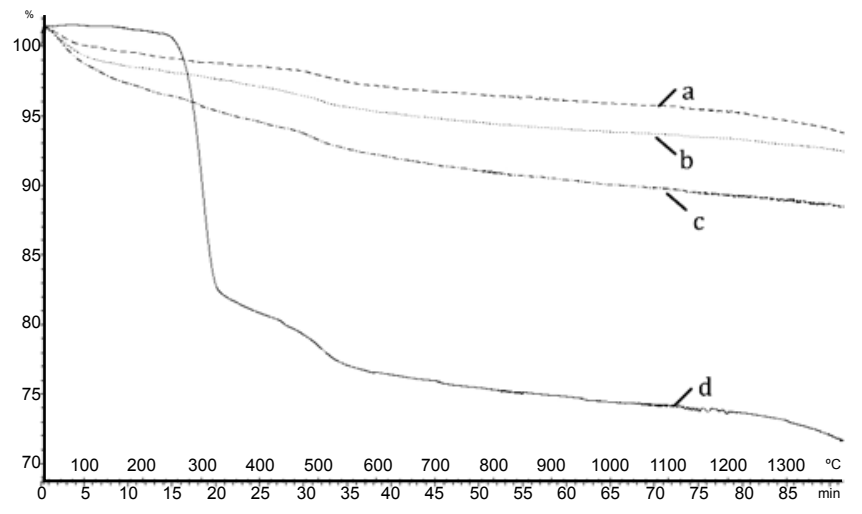

Figura 3: Curvas TG da bauxita calcinada (a), das bauxitas em solução de ácido clorídrico 1,0 mol.L $\mathrm{L}^{-1}$ (b) e 4,0 mol.L $\mathrm{L}^{-1}$ (c) e da bauxita in natura (d).

[Figure 3: TG curves of calcined bauxite (a), of bauxites in 1.0 mol.L.L (b) and 4.0 mol.L.-1 (c) HCl solutions, and of raw bauxite (d).] 


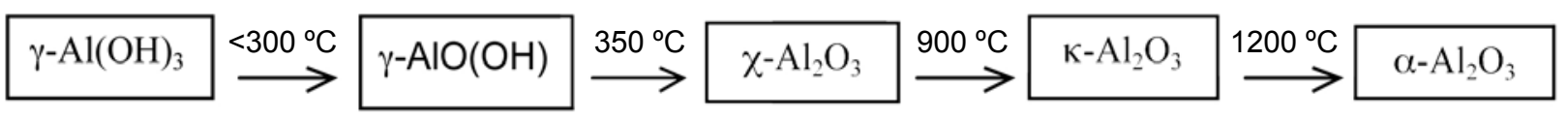

Figura 4: Etapas que acompanham a transformação da fase gibbsita em alumina alfa.

[Figure 4: The transformation of the gibbsite into alpha alumina phase occurs via solid state reactions.]

a $330{ }^{\circ} \mathrm{C}$, corresponde ao inicio da transformação da fase gibbsita em boehmita através das perdas de hidroxilas na forma de água. Entre 330 e $520{ }^{\circ} \mathrm{C}$, ocorre a segunda etapa de perda de massa de $3,83 \%$, a qual se refere à desidroxilação da fase boehmita levando a formação de óxidos de alumínio metaestáveis. Na terceira etapa de perda de massa 5,40\% ocorre a transformação destes óxidos de transição em alfa alumina via reações de estado sólido [11-13].

A seqüência de reações que acompanham a transformação da fase gibbsita em alfa-alumina pode ser observada na Fig. 4. A bauxita calcinada e as bauxita ativas com ácido clorídrico apresentam nas curvas TG pequena perda de massa de $2 \%$, entre 460 a $500{ }^{\circ} \mathrm{C}$, referente à conversão da fase boehmita - $\gamma$-AlO $(\mathrm{OH})$ - em óxido de alumínio metaestáveis através da desidroxilação. Acima de $950{ }^{\circ} \mathrm{C}$ os cristais de $\gamma-\mathrm{Al}_{2} \mathrm{O}_{3}$ aumentam de tamanho conduzindo à formação de $\delta-\mathrm{Al}_{2} \mathrm{O}_{3}$ e $\theta-\mathrm{Al}_{2} \mathrm{O}_{3}$ [9]. Aquecimento superior a $1000{ }^{\circ} \mathrm{C}$ produz $\alpha-\mathrm{Al}_{2} \mathrm{O}_{3}$.

A Fig. 5 apresenta o difratograma de raios $\mathrm{X}$ da bauxita in natura. A análise mineralógica por difração de raios $\mathrm{X}$ da bauxita in natura revela que este material é bem cristalizado e constituído, principalmente, pela fase cristalina de gibbsita $\left(\gamma-\mathrm{Al}(\mathrm{OH})_{3}\right.$, JCPDS 07-0324), seguida de outras duas minoritária de goethita $(\alpha-\mathrm{FeO}(\mathrm{OH})$, JCPDS 17-0536) e óxido de silício ( $\mathrm{SiO}_{2}$ - JCPDS 87-2096). Assim sendo, a bauxita presente em Poços de Caldas, MG, corresponde a bauxita tipo gibsítica, a qual é encontrada em regiões de clima tropical, como o Brasil, sendo a que apresenta maior interesse comercial $[2-3,10]$.

Os difratogramas de raios $\mathrm{X}$ da bauxita calcinada e das bauxitas ativada em ácido clorídrico 1,0 mol.L ${ }^{-1}$ e 4,0 mol.L ${ }^{1}$,

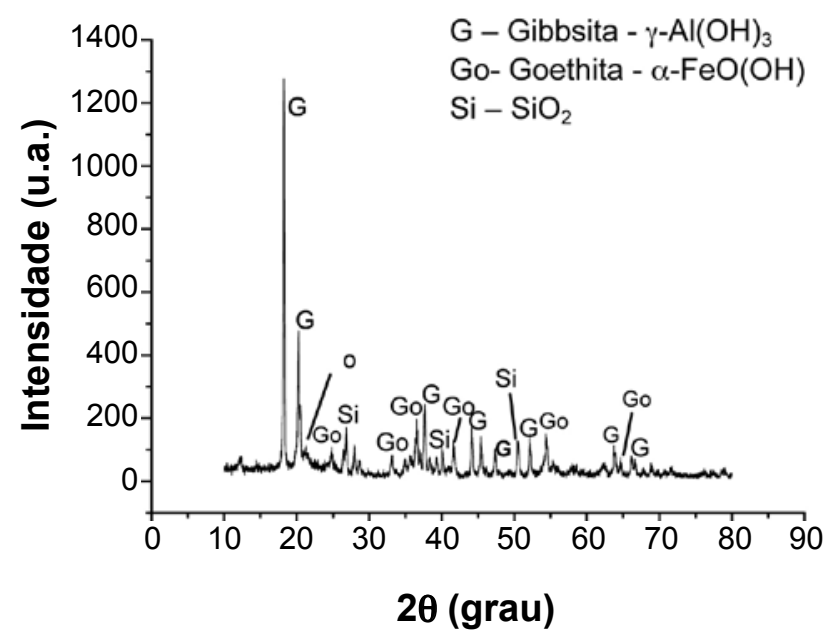

Figura 5: Difratograma de raios $\mathrm{X}$ da bauxita in natura.

[Figure 5: X-ray diffraction pattern of raw bauxite.] estão representados na Fig. 6 .

No difratograma da bauxita calcinada observam-se os picos referentes às fases boehmita $(\gamma-\mathrm{AlO}(\mathrm{OH})$, JCPDS 832384) e alfa-alumina $\left(\alpha-\mathrm{Al}_{2} \mathrm{O}_{3}, \mathrm{JCPDS} 42-1468\right)$. Essas fases são formadas durante o processo de calcinação da bauxita in natura, no qual ocorrem transformações dos hidróxidos de alumínio presentes no minério através das perdas das hidroxilas levando a formação de óxidos de alumínio metaestáveis, e posteriormente formação da fase alfa alumina via reações de estado sólido [2]. No caso da bauxita calcinada presente em Poços de Caldas, MG, o material é composto principalmente pela fase boehmita em detrimento da fase alfa-alumina. Isto ocorre devido ao processo de calcinação utilizado pela empresa, que apesar da bauxita in natura ser calcinada em forno rotativo a temperatura de cerca de $1100{ }^{\circ} \mathrm{C}$, essa temperatura é alcançada somente na superfície do sólido, enquanto que no interior deste a temperatura fica em torno de $600{ }^{\circ} \mathrm{C}$. Observam-se os picos referentes ao óxido de ferro $\left(\mathrm{Fe}_{2} \mathrm{O}_{3}\right.$, JCPDS 850599), os quais se devem a transformação da fase goethita $\alpha-\mathrm{FeO}(\mathrm{OH})$ - em hematita - $\mathrm{Fe}_{2} \mathrm{O}_{3}$ - também pela eliminação das hidroxilas presentes. Verificam-se também os picos referentes ao óxido de silício ( $\mathrm{SiO}_{2}$, JCPDS 87-2096). Acima de $1100^{\circ} \mathrm{C}$ começa a formar uma fase líquida, rica em $\mathrm{SiO}_{2} \mathrm{e}$ $\mathrm{Fe}_{2} \mathrm{O}_{3}$ [2]. Evidencia-se também que após a ativação ácida a bauxita sofre reduções das intensidades dos picos referentes aos óxidos de ferro e alumínio, o que é mais intenso para a amostra de bauxita ativada em ácido clorídrico 4,0 mol. $\mathrm{L}^{-1}$, no qual os picos localizados em $2 \theta$ igual a $33^{\circ} ; 36^{\circ}, 49^{\circ} ; 54^{\circ}$;

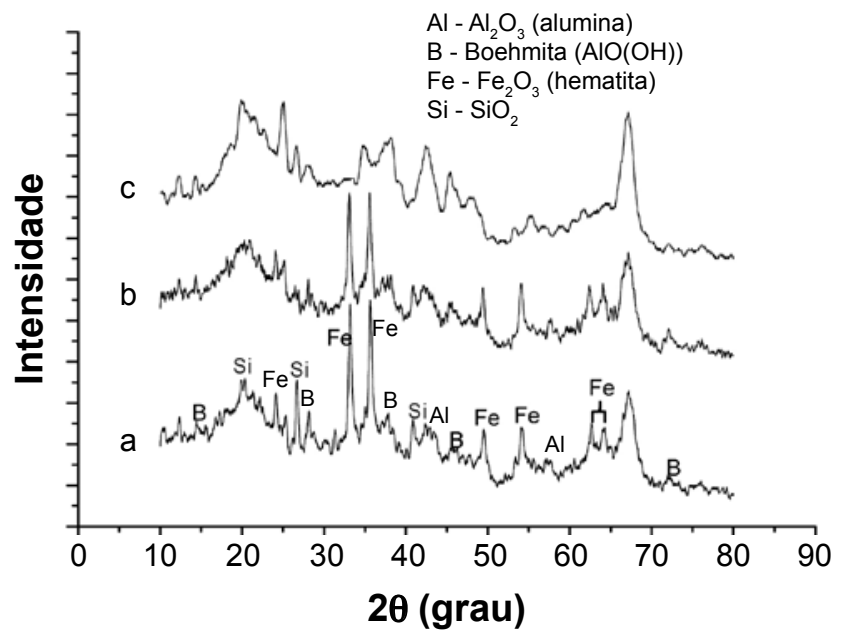

Figura 6: Difratogramas de raios $\mathrm{X}$ da bauxita calcinada (a) e das bauxitas ativada em solução de ácido clorídrico 1,0 mol.L ${ }^{-1}$ (b) e 4,0 mol.L-1 (c).

[Figure 6: X-ray diffraction patterns of: calcined bauxite (c), and of bauxites activated in 1.0 mol. $\mathrm{L}^{-1}$ (b) and $4.0 \mathrm{~mol} . \mathrm{L}^{-1}$ (a) HCl.] 
$62^{\circ}$ e $64^{\circ}$, correspondentes a fase hematita $\left(\mathrm{Fe}_{2} \mathrm{O}_{3}\right.$, JCPDS $85-0599)$, e os picos localizados em $2 \theta$ igual $28^{\circ}, 37^{\circ}$ e $72^{\circ}$, correspondentes a fase boehmita $(\gamma-\mathrm{AlO}(\mathrm{OH})$, JCPDS 832384), reduziram significativamente. Isso ocorre devido à dissolução de ferro e do alumínio em ácido clorídrico, diminuindo assim o teor destes óxidos no material após a lixiviação ácida.

A Fig. 7 ilustra as isotermas de adsorção/dessorção de $\mathrm{N}_{2}$ obtidas das bauxitas estudadas. Observa-se que a isoterma de adsorção/ dessorção de $\mathrm{N}_{2}$ da bauxita "in natura" (Fig. 7a) apresentou comportamento de curva típico de sólido que não apresenta mesoporosidade. Enquanto que as isotermas obtidas para a bauxita calcinada e para as bauxitas tratadas com ácido clorídrico (Figs. 7b-d) apresentam comportamento de isoterma do tipo IV. Este tipo de isoterma é característico de materiais mesoporos (poros intermediários entre 2 a 50 $\mathrm{nm}$ ). Observa-se o formato loop de histerese, fenômeno associado à condensação e evaporação capilar do gás nos poros, o que é observado neste tipo de isoterma. Verifica-se que a forma desta histerese é do tipo H3, a qual corresponde a materiais que apresentam poros com formato de cunha, cones ou placas paralelas [14].

Algumas características texturais dos materiais como a área superficial, volume, área e tamanho de poros, podem ser obtidas através de isotermas de adsorção e dessorção de $\mathrm{N}_{2}$. O método BET foi utilizado para o cálculo de área superficial. Este método consiste em obter a capacidade da monocamada, isto é, a quantidade de substância que cobriria toda superfície com uma monocamada adsorvida, a partir das isotermas de adsorção física, determinadas experimentalmente [14]. Para determinação do volume de poros e diâmetro médio de poros foi empregado o modelo BJH. A Tabela II apresenta os resultados da análise textural das bauxitas em estudo.

Pelos valores encontrados na Tabela II observa-se que a bauxita in natura apresenta baixo valor de área superficial total $\left(10,24 \mathrm{~m}^{2} / \mathrm{g}\right)$, o qual está relacionado com o baixo volume de microporos. O resultado do valor de área superficial total calculado pelo modelo de BET da bauxita in natura é consistente com o valor de bauxitas encontradas em varias regiões do Brasil, que é em média $16,55 \mathrm{~m}^{2} / \mathrm{g}$ [15]. Verifica-se aumento de doze vezes na área superficial total
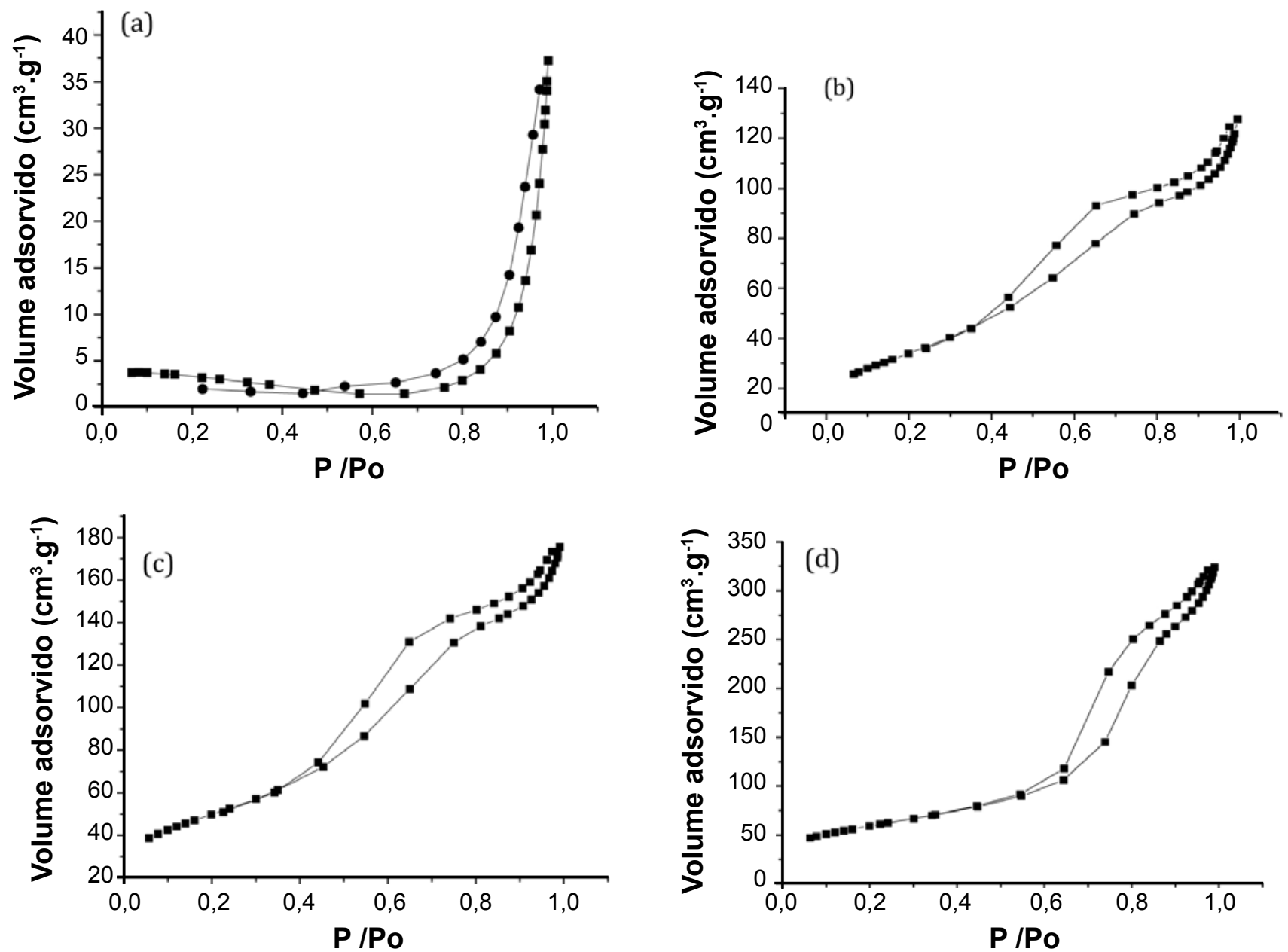

Figura 7: Isotermas de adsorção/dessorção de $\mathrm{N}_{2}$ da bauxita “in natura" (a), da bauxita calcinada (b) e das bauxitas ativadas em solução aquosa de $\mathrm{HCl} 1,0$ mol.L $\mathrm{L}^{-1}$ (c) e 4,0 mol.L $\mathrm{L}^{-1}$ (d).

[Figure 7: $N_{2}$ adsorption/desorption isotherms for raw bauxite (a), calcined bauxite (b) and for bauxites activated in an aqueous solution of 1.0 mol. $L^{-1}(c)$ and $4.0 \mathrm{~mol} . \mathrm{L}^{-1} \mathrm{HCl}(\mathrm{d})$.] 
Tabela II - Resultados de análise textural da bauxita "in natura", bauxita calcinada e das bauxitas ativadas com ácido clorídrico.

[Table II - Results of the textural analysis of raw bauxite, thermally activated calcined bauxite and of the bauxites activated with hydrochloric acid.]

\begin{tabular}{|c|c|c|c|}
\hline Amostra & $\begin{array}{c}\text { Área } \\
\text { superficial } \\
\text { total } \\
\left(\mathrm{m}^{2} / \mathrm{g}\right)\end{array}$ & $\begin{array}{c}\text { Diâmetro } \\
\text { de poros } \\
(\mathrm{nm})\end{array}$ & $\begin{array}{c}\text { Volume } \\
\text { de } \\
\text { poros } \\
\left(\mathrm{cm}^{3} / \mathrm{g}\right)\end{array}$ \\
\hline Bauxita "in natura" & 10,24 & 0,03 & 0,06 \\
\hline Bauxita calcinada & 124,77 & 5,64 & 0,21 \\
\hline $\begin{array}{l}\text { Bauxita ativada com } \\
\mathrm{HCl} 1 \mathrm{~mol} . \mathrm{L}^{-1}\end{array}$ & 178,75 & 5,85 & 0,29 \\
\hline $\begin{array}{c}\text { Bauxita ativada com } \\
\mathrm{HCl} 4 \text { mol.L } \mathrm{L}^{-1}\end{array}$ & 211,28 & 9,21 & 0,51 \\
\hline
\end{tabular}

e de aproximadamente quatro vezes no volume de poros da bauxita calcinada em relação à bauxita in natura. No processo de ativação térmica da bauxita as modificações físicas e químicas que ocorrem na estrutura do sólido são governadas principalmente pela desidratação das fases de hidróxidos de alumínio presentes [gibsita $\gamma-\mathrm{Al}(\mathrm{OH})_{3} \mathrm{e}$ boemita $\left.\gamma-\mathrm{AlO}(\mathrm{OH})_{3}\right][11]$, que resulta na formação de finos capilares na estrutura do sólido causando um aumento na porosidade e na área superficial. A partir dos resultados pode-se observar que o tratamento ácido imposto à bauxita calcinada aumentou a área superficial total das bauxitas tratadas, sendo que o aumento para a bauxita ativada com $\mathrm{HCl} 1 \mathrm{~mol} . \mathrm{L}^{-1}$ e 4 mol.L $\mathrm{L}^{-1}$ foi de, respectivamente, $43 \%$ e $69 \%$. Também se verifica aumento no diâmetro e volume de poros, e este aumento é mais pronunciado na ativação em solução ácida mais concentrada. Estas modificações na característica textural da bauxita, observada após a ativação ácida, deve-se à desorganização da estrutura, pois ocorre substituição dos íons interlamelares por íon $\mathrm{H}_{3} \mathrm{O}^{+}$, provável dissolução de impurezas e quebra de ligações químicas [10, 16]. Todas estas modificações causam o aumento da área superficial e do volume de poros.

\section{CONCLUSÕES}

O estudo de caracterização da bauxita presente em Poços de Caldas, MG, na região sudeste do Brasil, mostrou que o sólido apresenta altos teores de alumínio, acima de 50\% para bauxita in natura e teor próximo de $70 \%$ para bauxita calcinada, indicando um material com boas propriedades refratárias. Ferro e silício estão presentes em baixos percentuais; e cálcio, magnésio, potássio e sódio foram determinados em níveis de traços. O alumínio está presente na bauxita in natura na fase cristalina de gibbsita $\left[\gamma-\mathrm{Al}(\mathrm{OH})_{3}\right]$ e o ferro na fase cristalina de goethita $[\alpha-\mathrm{FeO}(\mathrm{OH})]$, os quais são convertidos em fases de óxido metaestáveis de alumínio e ferro com o processo de calcinação. Em relação ao silício, esse se encontra na forma de óxido de silício $\left(\mathrm{SiO}_{2}\right)$, tanto para a bauxita in natura quanto para a bauxita calcinada. Com relação às propriedades texturais da bauxita in natura verificase característica de sólido com ausência de mesoporosidade, com baixos valores de área superficial total, diâmetro e volume de poros. Entretanto, o processo de calcinação proporcionou aumento considerável de área superficial, tamanho e volume de poros, além de mudanças na característica do sólido para mesoporoso, com poros no formato de cunhas, cones ou placas paralelas. $\mathrm{O}$ processo de ativação ácida da bauxita calcinada proporcionou aumento da área superficial total e do volume e diâmetro dos poros, sendo que esse acréscimo foi proporcional ao aumento da concentração de ácido, pois em concentrações mais altas de ácido maiores proporções de íons ferro são trocados por $\mathrm{H}^{+}$. Assim, a ativação ácida da bauxita pode ser aplicada em sínteses ou processos de adsorções que requeiram melhores características de poros.

\section{AGRADECIMENTOS}

À FINEP pelo suporte financeiro, à FUNAPE pela gestão dos recursos financeiros e à Mineradora Curimbaba Ltda. pela concessão das bauxitas.

\section{REFERÊNCIAS}

[1] P. S. Santos, Ciência e Tecnologia de Argilas, Editora Edgar Blücher Ltda, $2^{\text {nd }}$ Ed., vol. 1, S. Paulo, SP (1989) 45. [2] C. Pascoal, V. C. Pandolfelli, Cerâmica 46, 298 (2000) 76.

[3] V. R. L. Constantino, K. Araki, D. O. Silva, W. Oliveira, Química Nova 25, 3 (2002) 490.

[4] IBRAM - Instituto Brasileiro de Mineração - < http:// www.ibram.org.br $>$, acessado em 04/03/2008.

[5] T. F. Aquino, Beneficiamento químico da bauxita de Santa Catarina, Diss. Mestrado, Universidade Federal de Santa Catarina, SC (2007) 125.

[6] M. J. C. Rezende, Uso de argila brasileira como catalisador na produção de biodiesel, Tese Dr., Universidade Federal do Rio de Janeiro, RJ (2006) 129.

[7] C. Fernandes, C. Catrinescu, P. Castilho, P. A. Russo, M. R. Carrott, C. Breen, Appl. Catalysis A: Gen. 318 (2007) 108 .

[8] C. M. R. Prado, N. R. Antoniosi Filho, J. Anal. Appl. Pyrolysis 86 (2009) 338.

[9] J. E. A. Piluski, D. Hotza, Química Nova 31, 3 (2008) 1165 .

[10] B. R. Reddy, S. K. Mishra, G. N. Banerjee, Hydrometallurgy 51, 1 (1999) 131.

[11] H. S. Altundogan, F. Tümen, J. Chem. Technol. and Biotechnol. 78, 7 (2003) 824.

[12] S. S. Baral, S. N. Das, P. Rath, G. R. Chaudhury, Biochem. Eng. J. 34, 1 (2007) 69.

[13] J. T. Kloprogge, H. D. Ruan, R. L. Frost, J. Mater. Sci. 37, 6 (2002) 1121.

[14] F. Rouquerol, J. Rouquerol, K. Sing, Adsorption by Powders \& Porous Solids - Principles, Methodology and Applications, Academic Press, Londres, Inglaterra (1999) 155. 
[15] L. R. S. Villar, Estudo do adensamento e ressecamento de resíduos de mineração e processamento de bauxita, Tese Dr., PUC-Rio de Janeiro, RJ (2002) 133.
[16] F. R. D. Días, P. S. Santos, Química Nova 24, 3 (2001) 345.

(Rec. 14/12/2010, Rev. 08/08/2011) 